\title{
How Similar are Pharmacy Students and White Blood Cells? Curricular Content Reinforced Through Personification
}

Kenric B. Ware, PharmD

South University School of Pharmacy

\begin{abstract}
Description: This initiative sought to evaluate the use of personification to reinforce immunology concepts among pharmacy students. A two-part question posed to first year pharmacy students asked if they could physically become two white blood cells (WBCs), which would they choose and why. Students received instruction in immunology prior to providing their feedback. Demographics included campus of enrollment and gender designation. Student ratings 1 to 5 reflected approval levels toward this activity's usefulness (1: least; 5 most).

Key Findings: One hundred and ten of 117 students selected two WBCs they would physically become if possible (94\%). Less than twothirds of students were female (63\%) and the Columbia campus featured approximately a quarter of the students (24\%). The most and least common WBCs chosen, as first selections by campus and gender, were statistically significant being neutrophils and basophils, lymphocytes and eosinophils, respectively. The median approval values of the WBC personification activity by campus and gender were similar and did not reach statistical significance, 4.5 and 5, respectively.

Conclusion: Pharmacy students commended the personification activity for helping them learn the roles and responsibilities of WBCs. Unique and insightful rationales for the choices made for WBCs persisted among the students. In light of these favorable reviews, this type of activity can be adapted to other areas of pharmacy education.
\end{abstract}

Keywords: personification, white blood cells, immunology, pharmacy students

\section{Description of the Problem}

Immunology is typically a foundational component of various educational pursuits. However, one survey of Australian medical students concluded that immunology is less than thrilling and filled with nuances that are difficult to relate to clinical practice. ${ }^{1}$ Approximately 30 Ghanaian graduate students reported through questionnaires that receptiveness to immunology reflects both instructor creativities and infrastructure capabilities. ${ }^{2}$ In response to concerns such as these, researchers have utilized a board-game among medical students to underscore immunological contributions of $T$ and B-lymphocytes. ${ }^{3}$ A trading-card game was also successfully adapted for teaching immunology to high school seniors in Taiwan. ${ }^{4}$ The game was designed to influence students' knowledge of factors that control the immune system and students' receptiveness to interactive educational delivery.

Doctor of pharmacy (PharmD) programs are compelled to articulate how the immunology education their students receive aligns with the essentials of pharmacy practice. ${ }^{5}$ Although this charge applies broadly to all PharmD programs, ingenuity of educational delivery seems to rest at the institutional level. ${ }^{6}$ Augmentation of immunology instruction through ascribing human tendencies to nonhuman elements, a process known as personification, ${ }^{7}$ may be useful in pharmacy curricula.

Corresponding author: Kenric B. Ware, PharmD

South University School of Pharmacy

kbware@southuniversity.edu
Personification has a wide scope in the literature, ranging from educational strategies to advertising. ${ }^{7-9}$ The recurring theme of personification is to relate products to people. ${ }^{9}$ Expounding on this logic, personification can ostensibly connect students to studying by humanizing homework for greater retention long term. Students' understanding of immunology concepts, in particular white blood cell (WBC) responsibilities, may improve by associating WBCs' physiologic operations with their everyday life occurrences. In general, WBCs play a vital role in establishing, maintaining, and restoring the functions of immunology. ${ }^{10} \mathrm{WBC}$ s are subdivided into agranulocytes, e.g., lymphocytes and monocytes/macrophages, and granulocytes, e.g., basophils/mast cells, eosinophils, and neutrophils. ${ }^{10}$

\section{Statement of the Innovation}

The purpose of this activity was to employ personification as a reinforcement strategy supplemental to immunology lecture materials in studying WBCs. As each student has a different lived experience, personification allowed students to use their intrinsic natures to supplement instruction. In addition, a secondary aim was to explore patterns of WBC relatability among gender and campus of enrollment distinctions. Societal norms may influence perceptions that men and women have of themselves. Therefore, creativities produced in assuming characteristics of WBCs may fluctuate by gender. With the varying sizes of the campuses, students may assume different roles, which may impact the characteristics highlighted by their personifications.

A tertiary aim was an analysis of the type of WBC chosen. Each WBC contributes uniquely to overall immune maintenance. 
This activity functioned as a review of the didactic instructional material. As a result, it was important to gauge which aspects of WBC functionalities resonated the most with students and their corresponding rationales.

During the first of a nine-quarter didactic curriculum, in a three-year PharmD program, pharmacy students on the Savannah and Columbia campuses received immunology lectures as a subset of a Pathophysiology course. There were four, 70-minute_in-person/videoconference lectures, delivered by the author and devoted to WBC functionalities. These instructional periods took place during weeks nine and ten of a ten-week quarter. Eight percent of the grading allotment in the course consisted of participation activities. Of this allocation, two percent was available to students in exchange for completion of the assignment described herein. Participation called for students to answer: If you could physically become two WBCs, which two would you choose and why? Each WBC chosen and discussed corresponded to one percent of the graded participation activity. Students received credit for explanations that demonstrated connections between duties of their selected WBCs to distinct aspects of their personalities.

A word limit was not imposed on the assignment. Acceptable rationales included references to students' own personalities or those of others. While the provision of specific examples of their actual or hypothetical personalities would have been ideal, they were not required.

Following participation, students were asked to respond on a Likert scale, with 1 being the least beneficial and 5 being the most beneficial, to the question "How effective was this assignment as a learning technique in relation to other learning strategies used in the course?" The numerical value associated with the response to this one question constituted the "approval rating" variable used for statistical purposes. The deadline was one week from the date of assignment posting. The author served as the sole reviewer of each submitted entry.

Data relating the approval rating of the assignment in comparison to other educational activities within the course was coded as 1, referring to minimum approval, extending to 5 for maximum approval. Microsoft Excel housed the coded data prior to statistical analyses. Data corresponding to openended comments were prompted exclusively by the question "If you could physically become two WBCs, which two would you choose and why?" These data were analyzed by grouping key themes among the students' WBC identifications to evaluate trends in student explanations.

Descriptive statistics were used to categorize frequencies and percentages of WBC selections. The Chi-square test of homogeneity was used to evaluate whether the distributions of multinomial dependent variables, i.e., basophils/mast cells, eosinophils, neutrophils, lymphocytes, monocytes/ macrophages selected first and second differed by independent variables, i.e., campus of enrollment and gender. Mann-Whitney $\mathrm{U}$ analysis assessed whether the dependent variable, i.e., activity approval level, differed by independent variables, i.e., campus of enrollment and gender. Data analyses were performed using IBM SPSS Statistics for Windows, v25 (IBM Corp., Chicago, IL). A $p$-value of $<.05$ was considered statistically significant. The study was reviewed and approved by the Institutional Review Board (IRB) at South University.

\section{Critical Analysis}

One hundred and ten of the 117 students enrolled in the course $(94 \%)$ related two WBCs to their personalities. The remaining seven students did not complete the assignment. Of the total student sample, 93 of the 110 students $(85 \%)$ provided approval ratings of this learning activity. The median approval ratings generated by campus and gender $(5.0$ [Savannah Campus], 4.5 [Columbia Campus]; 5.0 [Females], 5.0 [Males]) respectively, were similar across both groups $(p=0.43$ and $p=0.62)$. One hundred and ten students elected to relate two WBCs to their personalities, comprising 220 total responses. However, of these 220 responses, 209 provided descriptive reasons for the WBC selections as stipulated by the assignment instructions (95\%). Table 1 summarizes student reflections and their WBC comparisons.

Eighty-seven of the 93 qualitative, open-ended comments associated with student approval ratings (94\%) regarded this academic exercise as an engaging way to study through uniquely relating themselves to the instructional material. From these remarks, students believed personalizing the material would be a good way to help with final examination preparations and for greater memory long-term. Of the remainder of the 93 open-ended statements, three took exception with the parameter of selecting only two WBCs and three other opinions expressed that there was insufficient instruction provided about the expected level of details from each student response. The differences observed among the first choices of WBCs in terms of campus $(p=.02)$ and gender $(p<.01)$ were statistically significant (Figure 1$)$.

Females were over three times more likely to identify with lymphocytes as opposed to males. Considering a key aspect of the lymphocyte that resonated with students was the $\mathrm{CD}_{4} \mathrm{~T}$ cell helper functionality, this finding was not surprising. As some perspectives view females as more nurturing and supportive than males, this result seems to align with prevailing gender perceptions. Males were roughly two times more likely to equate themselves to monocytes/macrophages than females. Students' prominent focus in this study was that of monocytes/macrophages chief responsibility being phagocytic (cell eating). Some sentiments regard males as 
having larger appetites than females. Therefore, this difference in gender responses is also not surprising.

Students on the Columbia campus that related to lymphocytes more than doubled those on the Savannah campus. There are fewer students enrolled on the Columbia campus than the Savannah campus. Perhaps this smaller number of students in Columbia creates more of a "family-feel" than is on display in Savannah. In turn, Columbia students may be more inclined to help each other more, mirroring the $\mathrm{CD}_{4} \mathrm{~T}$-cell helper functionality ascribed to lymphocytes.

Instructors can use these findings when constructing student group assignments. An emphasis on ensuring each group has an appropriate representation of both genders, in light of the intrinsic tendencies that each gender possesses, may be ideal. Additionally, instructors can be intentional about devising collaboration efforts among students on different campuses as students in each location perceivably have unique perspectives to contribute.

An 1986 account of the benefits of personification use in pharmacodynamics instruction for healthcare students concluded that the iterative process of personified writing confers a level of control of the subject matter that is superior to rote memorization. ${ }^{7}$ The authors instructed nursing students to equate aspects of their lives to drug therapies in terms of interaction capabilities, foreseeable adverse reactions, and monitoring parameters pertinent to a nursing professional. One student submission figuratively inhabited traits of an anti-anxiety drug, relating details of its manufacturing process, public perception, benefits, and precautions to personal experiences. While pharmacy students in this activity embodied WBC functionalities, the use of personification by both disciplines and topics reinforces its versatility as a teaching tool.

In addition, nursing educators turned to personification over two decades ago, ${ }^{8}$ providing evidence of personification's longevity. A "Bug of the Week" assignment prompted nursing students to identify with microorganisms through the construction of relatable images using various supplies available at their disposal. Students used food, crafts, and artistic sketches to portray their bugs. Students' formal presentation of the sculpted organisms to faculty and peers, while explaining and eating the edible displays, reportedly enhanced familiarity with microorganisms' life cycles in an interactive manner. This activity purported to heighten both differentiation and integration skills among the nursing students. ${ }^{8}$ Similar to reflections of pharmacy students in this study, the nursing students attested to creativity and a deeper understanding of the subject matter emerging in both an engaging and lighthearted manner.
Limitations of the WBC personification activity completed here exist. Categorizations of the WBCs in this activity treated basophils and mast cells as being synonymous with the same approach used for macrophages and monocytes. While there are distinct differences among these cell types, ${ }^{10}$ the author grouped them together based on their similarities for ease of quantification. Furthermore, the activity design did not account for students who extensively (or minimally) studied immunology prior to pharmacy school. Although, any immunology training within this cohort prior to pharmacy school was minimal. Moreover, this concern appears neutralized by the activity's focus on individualized student learning as an opportunity for concentrated review.

In addition, better optimization of the activity's timing in the course could have occurred. Conducting the WBC personification activity in the beginning of the course with a planned debrief towards the end may have been ideal. Prompting students to review the concepts earlier could have highlighted points of confusion quicker and produced greater knowledge retention over time. Additionally, restricting the number of WBC selections to two could have limited the scope of students' review. The major concern with expanding WBC options to more than two was a dilution of the responses provided by students. However, the dislike of only selecting two WBCs may have affirmed a high interest level in the assignment overall.

\section{Next steps}

Possible adaptations of the methodology are feasible. Personification can further invigorate teaching and learning of different aspects of medication management, such as drug indications, side effects, counseling points, and drug-drug interactions. Moreover, initiation of an activity along these lines could occur as a group assignment, where responses exchanged among peers can allow participants to learn more about and from one another. Alternatively, instituting this activity among faculty and students on different campuses that orchestrate video technology-based curricula could help to develop a mutual rapport that may be a challenge for distance education. Furthermore, admission interviews could adopt an activity of this nature when getting to know prospective students better. Notably, no substantive accounts of this activity's influence on academic performance occurred in this implementation. However, this activity could be assessed through comparison of scores on the same immunology questions featured on the course final examinations administered to the pharmacy student cohort exposed to the WBC personification activity and a preceding or succeeding cohort that lacked this exposure.

This study highlighted the creativity of pharmacy students associating attributes of WBCs with their personal behaviors. Conducted in a low-stakes environment, pharmacy students remarked about the activity being supportive as opposed to 
punitive. Furthermore, pharmacy students touted this educational strategy as a fun and useful way to engage students in their own learning. Educators are encouraged by these findings to accommodate activities in classroom settings that appeal to their students' insightfulness and ingenuity.

Funding Support: None

Conflicts of Interest: None

\section{References}

1. Lee AY, Malau-Aduli BS. Medical students' learning experiences and perceptions of Immunology. Internet J Med Educ. 2013; 3(1):1-8.

2. Kwarteng $A$, Dissou-Arthur $Y$, Sylverken $A$, Frimpong $M$, Terkper SA, Owusu-Dabo E. Key drivers of graduate students' interest in the subject of Immunology in a tertiary institution in Ghana. Cogent Educ. 2018; 5(1):1-11. DOI: 10.1080/2331186X.2018.1498162

3. Eckert GU, Celia Michel Da Rosa A, Busnello RG, Melchior R, Masiero PR, Scroferneker ML. Learning from panel boards: T-lymphocyte and B lymphocyte self-tolerance game. Med Teach. 2004; 26(6):521-524. DOI: $10.1080 / 01421590412331285414$

4. Su T, Cheng M, Lin S. Investigating the effectiveness of an educational card game for learning how human Immunology is regulated. CBE Life Sci Educ. 2014; 13(3):504-515. DOI: 10.1187/cbe.13-10-0197
5. Accreditation Council for Pharmacy Education. Accreditation Standards and Key Elements for the Professional Program in Pharmacy Leading to the Doctor of Pharmacy Degree. Published 2015.

https://www.acpe-

accredit.org/pdf/Standards2016FINAL.pdf. Accessed January 5, 2019.

6. Zhao Y, Ho D, Oldham B, Dong B, Malcom D. Current status of immunology education in US schools and colleges of pharmacy. Am J Pharm Educ. 2018; in press:

https://www.ajpe.org/doi/pdf/10.5688/ajpe6994

7. Lantz JM, Meyers GD. Critical thinking through writing: using personification to teach Pharmacodynamics. J Nurs Educ. 1986;25(2):64-66. DOI: 10.3928/0148-4834-19860201-07

8. Gruca JM, Douglas MR. Bug of the week: A personification teaching strategy. J Nurs Educ. 1994;33(4):153-154. DOI: 10.3928/0148-483419940401-07

9. Brown S. It's alive inside! A note on the prevalence of personification. Ir Mark Rev. 2011; 21(1/2):3-11.

10. Grossman S. Blood Cells and the Hematopoietic System. In: Grossman S, Porth CM, ed. Porth's Pathophysiology: Concepts of Altered Health States. 9th ed. United States of America: Wolters Kluwer I Lippincott Williams \& Wilkins; 2014. 
Table 1. Excerpts of pharmacy students' self-disclosed commonalities with WBCs ${ }^{\ddagger}$

WBCs

Basophils/

Mast Cells

Eosinophils

Neutrophils

Lymphocytes

Monocytes/Macrophages ㄴarger, phagocytic cell

common

- Small cell size

$\square$ Histamine, heparin, parasitic infections signaling properties

- Early arrival to site of infection / injury

$\square$ Small, phagocytic cell neutrophils) to mature

‡。CD4 T-helper cells

${ }^{\ddagger}$ NK cells
Pharmacy student relatability

Total

- Uniqueness

count

- Lower amount in the body

- Scarcity, one of a kind, least

- Short in stature

$\square$ Internal substances released in adversity

$\square$ Annoying personality towards others leukotrienes, in granules

- Influential in response to

$\square$ Lower amount in the body *Anti-parasitic, malignancy

*Higher amount in the body

- Phases of growth pattern; from immature (banded (segmented neutrophils)

$\square$ Memory B cell lymphocytes

* Antibody-producing B cells
- Spew toxic comments at parasitic individuals

$\square$ Act in severe situations to help others

*Alerting others when necessary

- Enjoy being first person to fix a problem - First line of defense on sporting teams

$\square$ Love different food in small amounts

* Strength in numbers

- A time to joke, a time to get work done
$7 \%$
$8 \%$

$27 \%$

$34 \%$

- Like helping family with issues that arise $\square$ Good recall of facts that helps both at work and school

- Take pride in helping classmates with academic coursework

* Fight harmful things

* Different types of antibodies reflect diverse personalities

- Prone to act first, think later

- Nonspecific killer instincts

- Ingest others' problems

- Always eat and eat a lot

- Engulf lower grades; turn them into

higher grades 
Figure 1. Distributions of first WBC selections among participants by campus and gender

\section{WBC Selections by Campus and Gender}

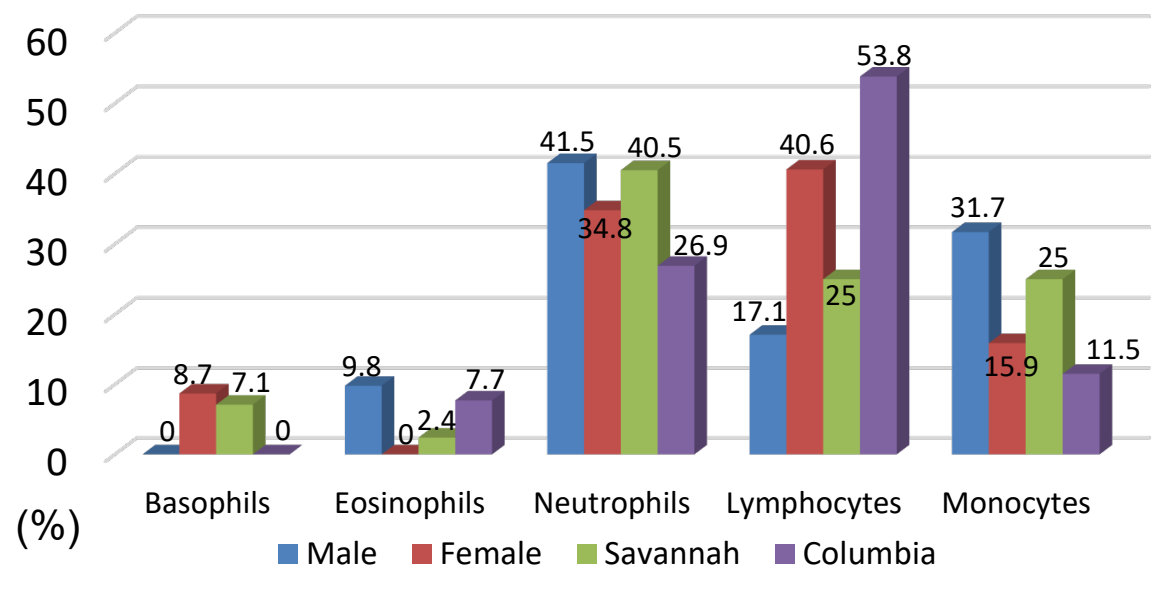

N =110; 69 Females; 41 males; 84 Savannah; 26 Columbia 